\title{
Evidence for a base triple in the free HIV-1 TAR RNA
}

\author{
HENDRIK HUTHOFF, ${ }^{\mathbf{1}}$ FREDERIC GIRARD, ${ }^{\mathbf{2}}$ SYBREN S. WIJMENGA, ${ }^{\mathbf{2}}$ and BEN BERKHOUT ${ }^{\mathbf{1}}$ \\ ${ }^{1}$ Department of Human Retrovirology, Academic Medical Center, University of Amsterdam, Amsterdam, the Netherlands \\ ${ }^{2}$ Department of Biophysical Chemistry, University of Nijmegen, Nijmegen, the Netherlands
}

\begin{abstract}
We propose the existence of a novel base triple in the HIV-1 TAR hairpin. This triple is supported by covariation of loop residue 31 with residue 22, which is part of an unusual base pair with U40 below the 3-nucleotide bulge. A set of mutants was constructed to test the involvement of bases A22, U31, and U40 in a triple interaction. RNA structure probing, trans-activation assays, and structure modeling are consistent with the existence of this base triple in a bent conformation of the free TAR element. However, disruption of the base triple does not affect binding of a Tat-derived peptide. We therefore compared the structure of free and Tat-bound TAR RNA by footprinting and site-specific cross-linking analyses. These studies indicate that the Tat arginine-rich motif, in addition to its known binding site at the bulge, is in close contact with U31 in the TAR loop. Because binding of Tat to TAR is known to coincide with the formation of a base triple with residues U23, A27, and U38, we hypothesize that Tat binding and the associated straightening of TAR triggers the disruption of the (A22-U40)U31 triple.
\end{abstract}

Keywords: TAR; riboswitch; HIV-1; base triple; tertiary structure

\section{INTRODUCTION}

The HIV-1 Tat protein is a potent activator of transcription from the viral LTR promoter and is essential for virus replication (Fisher et al. 1986; Dimitrov et al. 1993; Cullen 1998). Trans-activation is dependent on the interaction of Tat with the trans-acting responsive element (TAR), which is a 59-nt RNA hairpin present at the extreme $5^{\prime}$ end of all HIV-1 transcripts (Muesing et al. 1987; Feng and Holland 1988; Berkhout et al. 1989). The Tat-TAR complex represents one of the most intensively studied RNA-protein interactions. Recombinant Tat protein binds specifically to TAR in vitro (Dingwall et al. 1989), as do synthetic peptides carrying the C-terminal arginine-rich domain of Tat (Weeks et al. 1990; Weeks and Crothers 1991, 1992). Through mutational analysis and chemical interference experiments, the Tat-binding site has been mapped to the 3-nt bulge and flanking base pairs in the TAR hairpin (Berkhout and Jeang 1991; Weeks and Crothers 1991; Churcher et al. 1993). The Tat-TAR binary complex recruits the Cyclin T subunit of the P-TEFb complex, which associates with the apical loop of the TAR element (Wei et al. 1998; Richter et

Reprint requests to: Ben Berkhout, Department of Human Retrovirology, Academic Medical Center K3-110, University of Amsterdam, Meibergdreef 15, 1105 AZ Amsterdam, the Netherlands; e-mail: b.berkhout@ amc.uva.nl; fax: +31-20-691-6531.

Article and publication are at http://www.rnajournal.org/cgi/doi/ 10.1261/rna.5161304. al. 2002a,b). This results in phosphorylation of RNA polymerase II, which enhances transcriptional elongation at the LTR promoter (Marciniak and Sharp 1991; Parada and Roeder 1996; Bieniasz et al. 1999).

The structure of TAR RNA has been studied extensively, both in its free and Tat-bound form. Free TAR has a relatively flexible structure due to the kink, or bend, introduced by the 3-nt bulge (Zacharias and Hagerman 1995; Aboul-ela et al. 1996; Al Hashimi et al. 2002). A recent NMR study demonstrated that the TAR hairpin can adopt two distinct conformations in the absence of Tat (Long and Crothers 1999). One conformer has the first bulged nucleotide, U23, stacked on top of the preceding A22-U40 base pair. The second conformer has a bulge that extrudes from the helix, allowing the flanking stems to stack coaxially as observed in the crystal structure (Ippolito and Steitz 1998). This conformational versatility was confirmed in a recent study, which demonstrated that free TAR can sample conformational states with variable interhelical bends (Al Hashimi et al. 2002). Distinct structures have been suggested for the TAR loop, and there is recent evidence that the apical loop is stabilized by a cross-loop base pair between residues C30 and G34 (Colvin and Garcia-Blanco 1992; Critchley et al. 1993; Jaeger and Tinoco 1993; Kulinski et al. 2003).

Significant structural changes in TAR have been observed upon binding of the complete Tat protein, Tat-derived peptides, and small molecular mimics such as argininamide. In general, the changes induced by Tat and its derivatives are 
similar, because the specificity of Tat binding is mostly dictated by a single arginine residue (Calnan et al. 1991; Tao and Frankel 1992). Upon binding of Tat or a Tat derivative, the bases in the bulge become unstacked and are extruded from the helical axis, which allows coaxial stacking of the two helical stems (Puglisi et al. 1992; Aboul-ela et al. 1995; Long and Crothers 1999). This conformational change reduces the degree of bulge-induced bending such that TAR is straightened when bound by Tat (Zacharias and Hagerman 1995). Furthermore, the phosphate backbone along the 3-nt bulge becomes inverted upon Tat binding, which is accompanied by the formation of a (A27-U38)U23 base triple (Puglisi et al. 1992, 1993). Although the existence of the base triple was questioned at first (Aboul-ela et al. 1996), it gained support from additional NMR and molecular dynamics studies on the TAR hairpin of HIV-1 (Long and Crothers 1999; Nifosi et al. 2000) and HIV-2 (Brodsky et al. 1998; Hennig and Williamson 2000).

In this study, we propose the existence of a novel base triple in the free TAR structure that is different from the triple formed upon Tat binding. The triple interaction in the free TAR RNA coincides with the bent structure of the hairpin, which allows positioning of loop residue U31 in proximity with the A22-U40 base pair below the bulge. We hypothesize that the Tat protein disrupts this triple in the free TAR RNA by interacting with residue U31, straightening of the TAR hairpin, and the formation of the known Tat-dependent (A27-U30)U23 base triple.

\section{RESULTS}

\section{Comparative sequence analysis suggests the existence of a base triple with residues A22, U31, and U40}

We performed a comparative analysis of 722 TAR sequences from the Los Alamos HIV sequence database and noticed a covariation of loop position 31 with position 22, which is part of an unusual base pair below the 3-nt bulge (Fig. 1). In most HIV-1 isolates, the $22-40$ base pair is of the A-U type and loop residue 31 shows a marked preference for $\mathrm{U}$ (Table 1). In some HIV-1 isolates of subtypes A and E the $22-40$ base pair is G-U and residue 31 shows a preference for C. Finally, all isolates of the $\mathrm{O}$ (outlier) group have a G22-C40 base pair and always a $\mathrm{C}$ at position 31. In total, we scored $619 \times \mathrm{U}$ and only $40 \times \mathrm{C}$ for residue 31 when there is an A at position 22 (A22-U40 base pair), and only $3 \times \mathrm{U}$ and $58 \times \mathrm{C}$ when a $\mathrm{G}$ is present at position $22(\mathrm{G} 22-\mathrm{U} 40$ and G22-C40 base pairs). Such a coupled covariation between the residues at positions 22, 31, and 40 is indicative of either an alternative secondary structure in which the residues interact as mutually exclusive base pairs or of a base triple interaction (Gultyaev et al. 2000). Using the Mfold program, we found no evidence for alternative secondary structures of TAR in which residues 22 and 31 interact directly (Zuker 1989; Mathews et al. 1999; Zuker and Turner 1999).

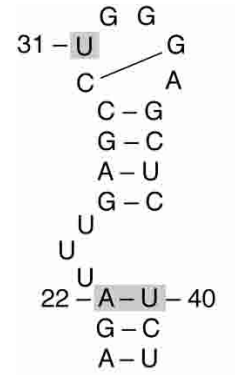

HIV-1: LAI (B)

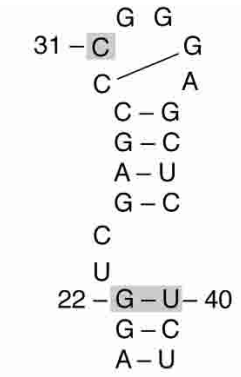

HIV-1: subtype $A$ and $E$

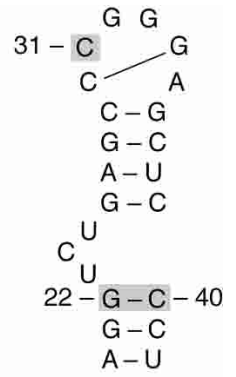

HIV-1: O group
FIGURE 1. Secondary structure models of TAR elements from different HIV-1 subtypes. Only the top part of the hairpin is shown, with the subtype B isolate LAI on the left. The TAR structures found in subtypes A and E (group $\mathrm{M}$ ) and all group $\mathrm{O}$ isolates have an $\mathrm{A}-\mathrm{U}$ to G-C covariation of base 22 with 31 . The identity of the $22-40$ base pair is $\mathrm{A}-\mathrm{U}, \mathrm{G}-\mathrm{U}$, or $\mathrm{G}-\mathrm{C}$.

The comparative sequence analysis thus suggests the possibility of a base triple involving residues 22,31 , and 40 .

In spite of the coupled covariation between the 22-40 base pair and loop residue 31, we observed that the Watson-Crick type complementarity is violated by mismatch mutations in $6.2 \%$ of the sequences analyzed. For comparison, mismatches in regular base pairs of the TAR stem occur between $0.3 \%$ (e.g., A27-U38) and 4.6\% (e.g., C18G44) within this set of sequences. In fact, the mismatch frequency of $6.2 \%$ is rather low compared to the relatively high level of uncorrelated base changes associated with base triples in rRNA, tRNA, and group I introns (Gautheret et al. 1995; Tanner et al. 1997; Babin et al. 1999). Thus, this comparative sequence analysis presents strong phylogenetic support for a (22-40)31 base triple in the HIV-1 TAR element.

\section{Site-directed mutagenesis and RNA structure probing of the (A22-U40)U31 triple}

To directly test the possibility that bases A22, U31, and U40 form a base triple, we constructed a set of mutants in which the putative triple is either disrupted or substituted by a (G-C)C triple (Fig. 2A). Mutant 1 contains a U-to-C sub-

TABLE 1. TAR sequence variation at positions 22,31 , and 40

\begin{tabular}{lcccr}
\hline $31 \rightarrow 22-40$ & A & G & U & C \\
\hline A-U & - & 1 & $\mathbf{6 1 9}$ & 40 \\
G-U & - & - & 3 & $\mathbf{4 3}$ \\
G-C & - & - & - & $\mathbf{1 5}$ \\
U-U & - & - & - & 1
\end{tabular}

Numbers in bold indicate Watson-Crick complementarity between residues 22 and 31 . 
A

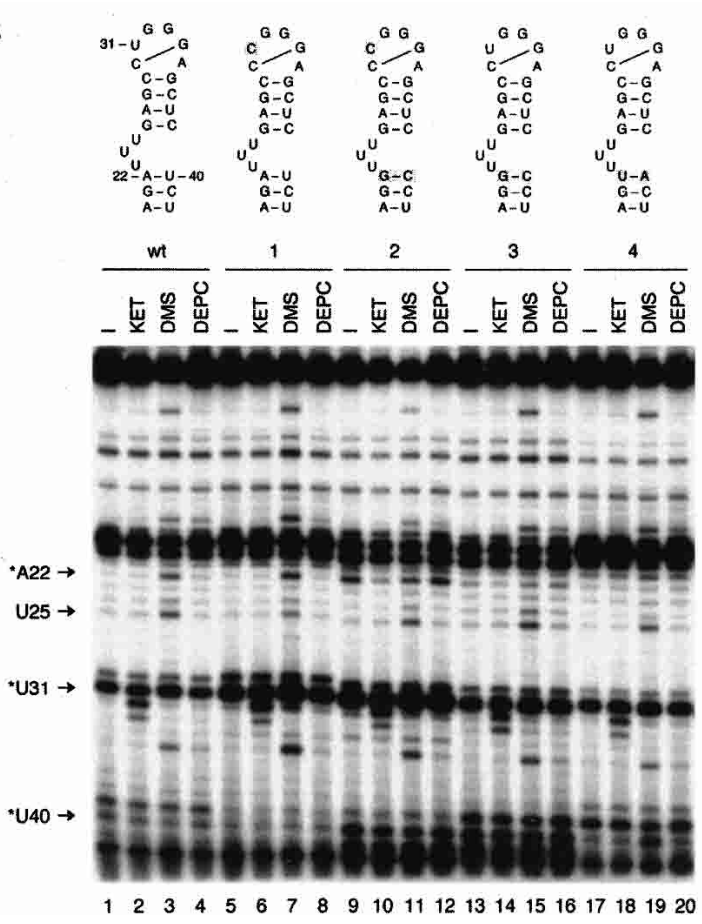

B
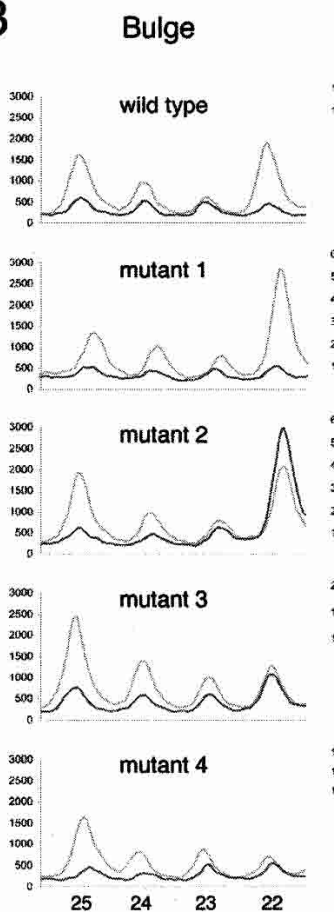

Loop
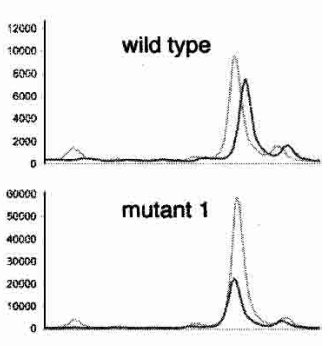

mutant 2
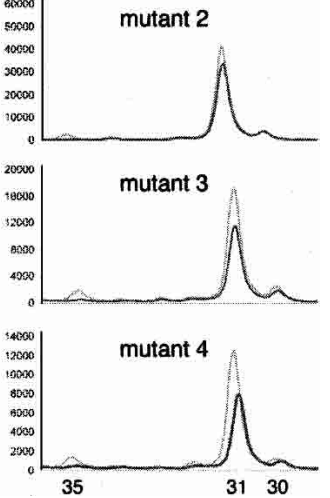

FIGURE 2. Chemical structure probing of wild-type and mutant TAR RNA. (A) Autoradiograph of primer extension reactions to map modified nucleotides. The wild-type and mutant TAR elements are shown on top, with substitutions marked in grey. TAR RNA was left untreated (-; lanes $1,5,9,13,17$ ) or incubated with kethoxal (KET; lanes 2, 6,10,14,18), DMS (lanes 3,7,11,15,19), and DEPC (lanes 4,8,12,16,20). Nucleotides marked by arrows indicate positions where differential modification is observed between the wild-type and mutant RNA. The gel is representative of three independent experiments. (B) Densitograms of the gel shown in A highlighting DMS modification in the bulge (left column) and loop (right column) regions.

stitution at position 31 , resulting in a mismatch between positions 22 and 31. Mutant 2 also contains the U31C substitution and the A22-U40 base pair is substituted by G22$\mathrm{C} 40$, which introduces the putative $(\mathrm{G} 22-\mathrm{C} 40) \mathrm{C} 31$ base triple observed in the O group of HIV-1 isolates. Mutant 3 contains the G22-C40 base pair alone, and in mutant 4 the A22-U40 base pair is reversed to U22-A40, resulting in a mismatch between positions 22 and 31 in both mutants.

We performed structure probing on the wild-type and mutant TAR RNA using the chemical probes kethoxal, DMS, and DEPC. The probing results with the wild-type TAR are in excellent agreement with the proposed secondary structure of TAR. The loop residues U31 and A35 react with DMS (Fig. 2A, lane 3, untreated control in lane 1), and G32 and G33 are accessible to kethoxal (Fig. 2A, lane 2). Loop residues C30 and G34 are protected from modification by DMS and kethoxal, respectively, which is consistent with the C30-G34 cross-loop base pair (Critchley et al. 1993; Richter et al. 2002a; Kulinski et al. 2003). Within the TAR stem, the two single nucleotide bulges $\mathrm{C} 5$ and A17 are readily identified by DMS and DEPC reactivity (Fig. 2A, lanes 3,4). Bases U24 and U25 within the bulge are also DMS reactive, whereas $\mathrm{U} 23$ is only weakly reactive (Fig. 2A, lane 3). The weak reactivity of $U 23$ is in agreement with previous NMR studies, which demonstrated that U23 is stacked on top of the A22-U40 base pair (Puglisi et al. 1992;
Aboul-ela et al. 1995, 1996; Long and Crothers 1999). We observed a significant DMS reactivity of A22, which forms a base pair with U40. Residue A22 has previously been shown to react with DEPC and DMS (Weeks and Crothers 1991), and NMR analyses indicated that the A22-U40 base pair has a distorted geometry with a widened major groove (Aboul-ela et al. 1995, 1996).

Each mutant maintains the characteristic reactivity profile of the TAR hairpin, for example, reactivity of the single nucleotide bulges C5 and A17, U24 and U25 in the 3-nt bulge and G32 and G33 in the apical loop (Fig. 2A). However, significant differences were observed in the extent of modification of residues 22 and 31 . The U31C substitution in mutant 1 results in a significantly stronger reactivity of A22 as compared to the bulge residues U24 and U25 in the wild-type TAR (Fig. 2B, bulge: cf. wild type and mutant 1). This result is consistent with the disruption of an interaction between residues 22 and 31 . In addition, there is a dramatic decrease in reactivity of C31 in mutant 2 compared with mutant 1 (Fig. 5B, below). The protection of residue 31 in mutant 2 indicates that a base triple interaction has indeed been reconstituted in this mutant (Fig. 2B, loop: cf. mutant 1 and mutant 2). Analysis of mutants 3 and 4 showed only subtle increases in the reactivity of U31, but this is nonetheless in agreement with a disrupted interaction between A22 and U31. 


\section{Promoter activity and Tat-binding properties of mutant TAR constructs}

We next investigated the effect of the mutations in TAR on its role in viral gene expression. C33A cells were transiently transfected with wild-type and mutant LTR-luciferase reporter plasmids with and without a Tat-expressing plasmid. Differences in the transfection efficiency were controlled for by using the dual luciferase system. Wild-type LTR activity with Tat was set at $100 \%$ (Fig. 3A), corresponding to a 13-fold Tat induction (Fig. 3B). Each of the TAR mutants supports Tat-mediated trans-activation, but the efficiency is significantly reduced compared with the wild type. Among the TAR mutants, mutant 2 with the reconstituted (G22C40)C31 triple shows the highest Tat response and it reaches a wild-type level of 13-fold trans-activation (Fig.

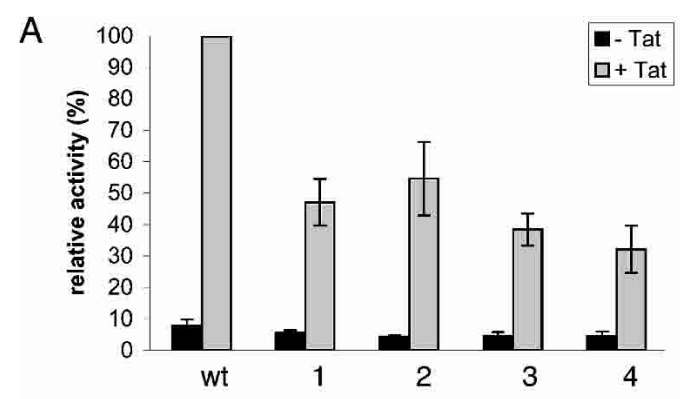

B

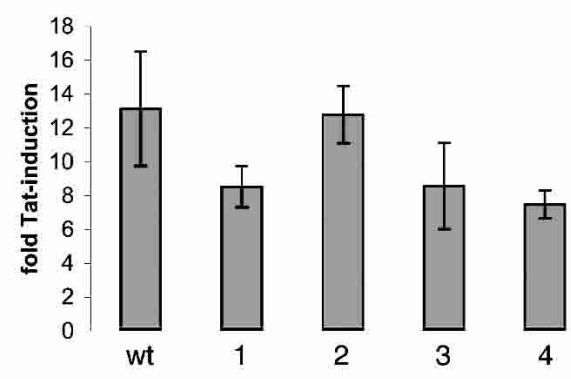

C

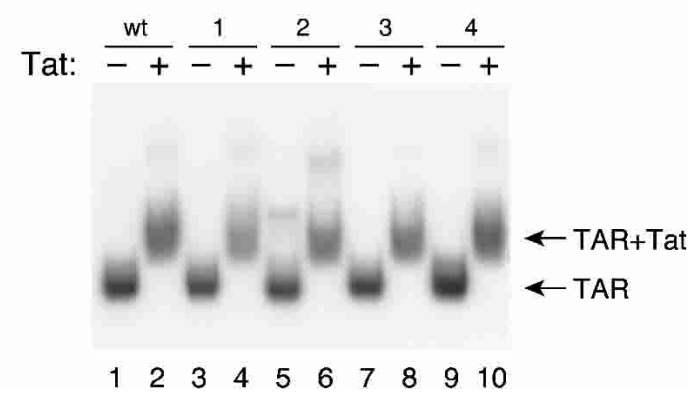

FIGURE 3. Analysis of Tat-mediated trans-activation of LTR-luciferase constructs with the wild-type and mutant TAR elements. (A) Relative promoter activities with and without cotransfection of a Tatexpressing plasmid. The luciferase activity measured in C33A cells for the wild-type construct with Tat was set at $100 \%$. The results are the average of six independent transfections. (B) Tat-mediated fold induction of the LTR promoter with wild-type and mutant TAR elements. (C) Binding of Tat peptide to wild-type and mutant TAR elements as analyzed by mobility shift experiments. Arrows indicate the position of free TAR and the TAR-Tat complex.
3B). Mutants 1, 3, and 4 with a disrupted base triple exhibit an approximate eightfold response. Thus, the reconstituted mutant 2 is more active than mutants 1 and 3, which contain the individual mutations present in mutant 2. These results support a role for the (A22-U40) U31 base triple in HIV-1 gene expression.

We also investigated the ability of the wild-type and mutant TAR hairpins to bind Tat. No differences were observed in Tat affinity between the wild-type and mutant TAR elements in band-shift assays with a 13 amino acid Tat peptide (Fig. 3C). Additional titrations with this peptide and an Escherichia coli-expressed recombinant form of the Tat protein did not yield detectable differences in Tat-binding affinity (results not shown). This is consistent with previous studies in which similar TAR mutants were shown to have essentially no effect on Tat binding (Weeks and Crothers 1991, 1992; Delling et al. 1992; Churcher et al. 1993). Thus, we cannot correlate the defects in LTR promoter activity with reduced Tat affinity of the TAR mutants. This suggests that the role of the (A22-U40)U31 base triple in HIV-1 gene expression acts at a level distinct from Tat binding.

\section{Modeling the (A22-U40)U31 triple in the free TAR hairpin}

The (A22-U40)U31 base triple most likely exists in the free TAR hairpin, as it is known to be highly bent, such that the loop comes in close proximity to the bulge (Aboul-ela et al. 1995, 1996; Huq et al. 1999; Al Hashimi et al. 2002). To assess whether formation of the (A-U)U triple in the TAR hairpin is physically possible, we sought to model this interaction using the available structural data on TAR (Aboulela et al. 1996; Long and Crothers 1999). In addition to the published NOE restraints (Aboul-ela et al. 1996), we introduced distance restraints to calculate conformers with (1) efficient C30-G34 pairing (CG ${ }^{\text {cross }}$ ) and (2) $\mathrm{CG}^{\text {cross }}$ together with a (A22-U40)U31 base triple interaction ((A$\mathrm{U}) \mathrm{U}+\mathrm{CG}^{\text {cross }}$, see Fig. 4). The presence of a cross-loop base pair between residues C30 and G34 was suggested by several studies and is consistent with our current structure probing results (Critchley et al. 1993; Nifosi et al. 2000; Richter et al. 2002a; Kulinski et al. 2003). For the C30-G34 base pair, we implemented classical CG base pairing restraints with loose borders. We faced more uncertainty on how to build up the base triple interaction. Nevertheless, based on the available TAR structures and the geometry of known (A-U)U triples, we chose to impose loose NOE restraints to bring U31 towards the A22 Hoogsteen side. U40 was kept paired to A22 in a Watson-Crick fashion with large distance borders.

In the ensembles of converged structures for both $\mathrm{CG}^{\text {cross }}$ and $(\mathrm{A}-\mathrm{U}) \mathrm{U}+\mathrm{CG}^{\text {cross }}$, the NOEs and dihedral experimental restraints were fully respected, with no NOE violation $(>0.5 \AA)$ and no dihedral violation $\left(>2^{\circ}\right)$. All short $1 \mathrm{H}-1 \mathrm{H}$ distances $(<5 \AA)$ were carefully checked to see whether they 

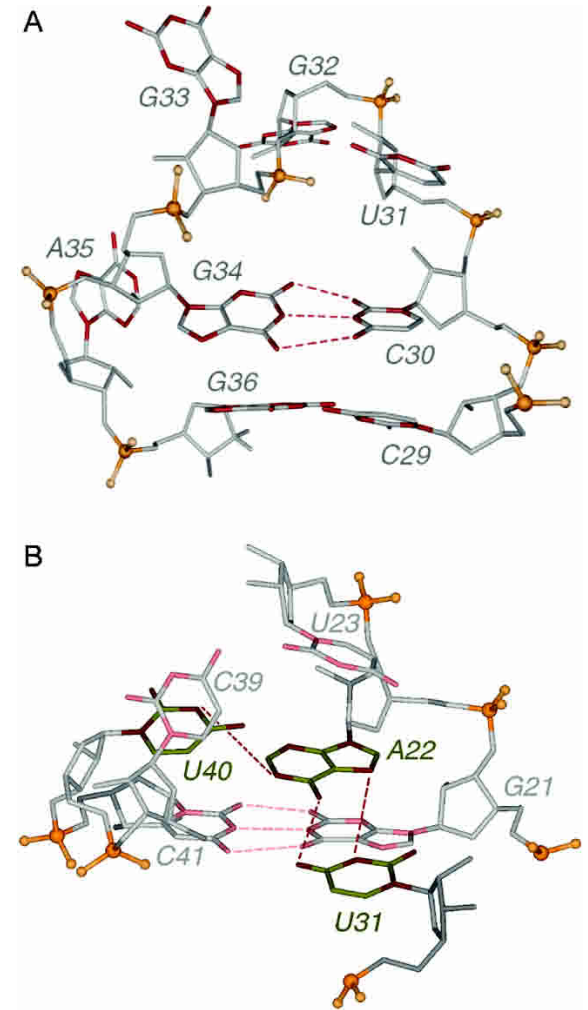

C

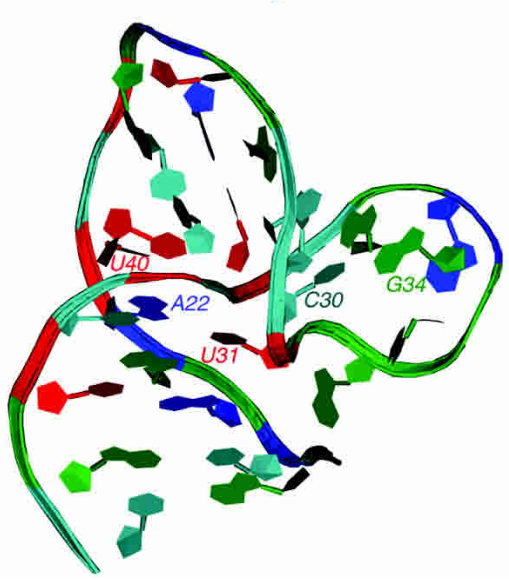

FIGURE 4. Structure modeling of the HIV-1 TAR hairpin. (A) Major groove view of the TAR apical loop with C30-G34 hydrogen bonds shown as dashed lines. Phosphate backbone atoms are shown in orange, oxygen and nitrogen from bases are highlighted in red. $(B)$ Detailed view of the proposed (A22-U31)U40 base triple interaction. Triplet bases are highlighted in green. $(C)$ Overall view of the TAR hairpin with the C30-G34 base pair and the (A22-U40)U31 triple in a ribbon representation. Guanines are shown in green, uracils in red, adenines in blue, and cytosines in cyan.

could be accounted for. For the $\mathrm{CG}^{\text {cross }}$ set, no inconsistencies between the experimental NOEs and the back-calculated distances were observed. For (A-U)U $+\mathrm{CG}^{\text {cross }}$, a small number of short sugar-sugar distances between C29 and C39 were observed in some of the derived models. In conclusion, in each independent $\mathrm{CG}^{\text {cross }}$ and (A$\mathrm{U}) \mathrm{U}+\mathrm{CG}^{\text {cross }}$ ensemble, we found molecules that fully ful- filled the distance restraints criteria derived from the previous experimental NMR restraints (Aboul-ela et al. 1996; Long and Crothers 1999).

NMR chemical shifts (CCS) are meaningful parameters to cross-validate the local conformation of RNA structures, as they can be predicted with high reliability (Wijmenga et al. 1997; Cromsigt et al. 2001). As proton assignments of the free TAR element are available (Long and Crothers 1999) we investigated whether our calculated structures agree with the experimental CCS data set. For the Aboul-Ela (Aboulela et al. 1996), $C G^{\text {cross }}$, and (A-U)U $+C^{\text {cross }}$ structural ensembles, we observed good agreement between the backcalculated and experimental CCS for residues in the helical parts (Table 2). Interestingly, implementation of the (A22U40)U31 triple interaction leads to highly bent conformers for which the CCS prediction of the Tat binding pocket is better than what is derived for the helical stems: considering the Aboul-Ela, $\mathrm{CG}^{\text {cross }}$, and (A-U)U $+\mathrm{CG}^{\text {cross }}$ models, the mean deviation for the bulge is, respectively, $0.20,0.21$, and $0.14 \mathrm{ppm}$. The loop CCS shows a somewhat higher deviation $(0.2-0.3 \mathrm{ppm})$, which is likely to be due to the presence of multiple conformations. An interesting case is the loop residue U31: for the Aboul-Ela and (A-U)U + $\mathrm{CG}^{\text {cross }}$ models, the U31 CCS deviation is 0.07 and $0.37 \mathrm{ppm}$, respectively. A closer analysis of the Aboul-Ela models showed that in many of the structures, U31 points towards the major groove of the loop, allowing efficient stacking on top of $\mathrm{C} 30$ and leading to higher ring-current effects. In the $\mathrm{CG}^{\text {cross }}$ and (A-U)U $+\mathrm{CG}^{\text {cross }}$ models, when we considered only conformers with this kind of loop folding, U31 CCS became very well predicted (Fig. 5). In this subset, the prediction for other loop residues is as good as, and in some cases better than, the published structures (Aboul-ela et al. 1996). In summary, the C30-G34 cross-loop base pair and the (A22-U40)U31 triple are consistent with all structural information derived by solution NMR studies on the free TAR element, although no direct evidence for the hydrogen bonds is observed. Because the free TAR structure is considerably flexible, it is possible that both the cross-loop base pair and the triple are present transiently.

\section{RNA structure probing of free and Tat-bound TAR}

To identify structural differences between the free and Tatbound forms of TAR, we performed RNA structure probing with and without an arginine-rich 13-amino-acid Tat peptide (Fig. 6). Upon binding of the Tat peptide, several changes in the TAR RNA structure are apparent (Fig. 6B, lanes 3,5). To highlight changes for the bulge and loop regions, we plotted the reactivity profiles in Figure 6C,D,E. As expected, bulge residues U23, U24, and U25 are strongly protected from DMS modification by the Tat peptide (Fig. 6C). The reactivity of A22 is also lost, which is in agreement with the notion that the A22-U40 base pair adopts a canonical Watson-Crick geometry that stacks coaxially with 
TABLE 2. Mean CCS deviation per structural element, in parts per million

\begin{tabular}{lccc}
\hline & $\begin{array}{c}\text { Aboul-Ela et al. } \\
\text { models }\end{array}$ & $\begin{array}{c}\text { CG }^{\text {cross }} \\
\text { models }\end{array}$ & $\begin{array}{c}\text { CG }^{\text {cross }}+(\mathrm{A}-\mathrm{U}) \mathrm{U} \\
\text { triple models }\end{array}$ \\
\hline $\begin{array}{l}\text { Lower stem } \\
\quad \text { Res.: 19, 20, 21, 22, 40, 41, 42,43 }\end{array}$ & 0.15 & 0.16 & 0.22 \\
$\begin{array}{l}\text { Bulge } \\
\quad \text { Res.: 23, 24, 25 }\end{array}$ & 0.20 & 0.21 & 0.14 \\
$\begin{array}{l}\text { Upper stem } \\
\quad \text { Res.: 26, 27, 28, 29, 36, 37, 38, 39 }\end{array}$ & 0.19 & 0.19 & 0.19 \\
$\begin{array}{l}\text { Loop } \\
\text { Res.: 30, 31, 32, 33, 34, 35 }\end{array}$ & 0.19 & 0.21 & 0.29 \\
& & & $0.21^{\text {a }}$
\end{tabular}

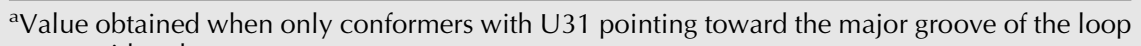
are considered.

of $\mathrm{U} 31$ is due to a direct interaction with Tat.

\section{Site-specific cross-linking of free and Tat-bound TAR}

To further investigate the possibility that U31 interacts directly with the arginine-rich motif in the Tat-TAR binary complex, we performed a sitespecific cross-linking experiment. A 27-oligomer comprising the top part of TAR with a photoreactive 4-thiouridine at position 31 was synthesized (Fig. 7A). UV-induced cross-linking was performed with ${ }^{32} \mathrm{P}$-end-labeled RNA in the absence and presence of

G26-C39 upon binding of Tat (Long and Crothers 1999). However, we cannot exclude the possibility that A22 is protected by the peptide itself. Differential reactivity is also observed in the TAR loop upon binding of the Tat peptide. U31 is protected from DMS by the Tat peptide (Fig. 6D), and residues G32 and G33 are more reactive to kethoxal in the presence of Tat (Fig. 6E), indicating that binding of Tat to the bulge influences the conformation of the loop. The Tat-mediated protection of U31 suggests a direct interaction of the arginine-rich peptide with the TAR loop. In fact, a Tat-dependent footprint in the TAR loop has been observed previously in assays with ribonucleases $\mathrm{A}$ and $\mathrm{T} 1$, in which case protection may be due to steric hindrance (Harper and Logsdon 1991). Because we observed the same effect with small chemical probes it is likely that protection

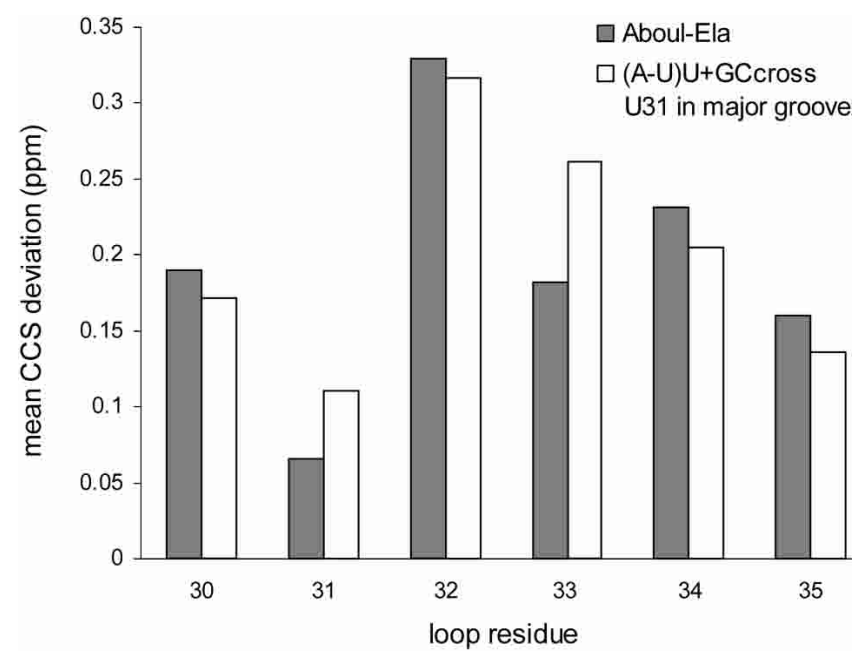

FIGURE 5. Mean CCS prediction in the apical loop for TAR models from the study by Aboul-Ela et al. (1996) and the (A-U)U + GC $C^{\text {cross }}$ models computed in this study. The comparison demonstrates that the restraints imposed for the (A22-U40)U31 triple, in conjunction with the C30-G34 base pair, are compatible with the previous NMR study. the Tat peptide. The samples were loaded on a denaturing polyacrylamide gel to identify and to excise cross-linked species (Fig. 7B). Cross-linking of the free TAR RNA produced two slow migrating species, termed X1 and X2 (Fig. 7B, lane 2). Without UV exposure, no cross-linked species were obtained (Fig. 7B, lane 1). This result indicates that U31 cross-links to sites within the TAR RNA in the absence of Tat, which would be consistent with the involvement of $\mathrm{U} 31$ in the (A22-U40)U31 base triple of free TAR. In principle, these cross-links could also be intermolecular, but we have not observed a significant amount of TAR dimers on native gels to support this possibility (results not shown). The cross-linked product X2 is specifically lost in the presence of Tat peptide, indicating that it corresponds to an interaction that is specific for free TAR RNA (Fig. 7B, lane 3). A novel fast migrating cross-linked species, $\mathrm{X} 3$, is observed with Tat, suggesting that it is an RNA-protein crosslink (Fig. 7B, lane 3). Indeed, the migration of this crosslinking product was sensitive to treatment with proteinase $\mathrm{K}$ (result not shown). The $\mathrm{X} 3$ species appears as a smear, but it migrates as a discrete band that is distinct from the uncross-linked RNA on shorter exposures (Fig. 7B, lane $3^{*}$ ).

To identify the sites that cross-link to U31, we performed partial hydrolysis of the gel-excised cross-link products. RNAse T1 digestion and partial alkaline hydrolysis of uncross-linked TAR were performed to provide an RNA sequence ladder (Fig. 7C, lanes 1,2). The hydrolysis ladder of the $\mathrm{X} 1$ and $\mathrm{X} 2$ samples covers the entire length of the molecule (Fig. 7C, lanes 3,4). The same result was obtained when the RNA was labeled at the $3^{\prime}$ end instead of the $5^{\prime}$ end (result not shown). Because there is no gap in the hydrolysis ladders of $\mathrm{X} 1$ and $\mathrm{X} 2$, the residues involved in these cross-links could not be identified. This could be due to the nature of the covalent bond formed upon crosslinking, which may be as susceptible to hydrolysis as the RNA phosphate backbone. The hydrolysis ladder of X3 terminates at the position of the 4-thiouridine cross-linker, U31. The $3^{\prime}$ end-labeled sample also yielded a stop at po- 
A

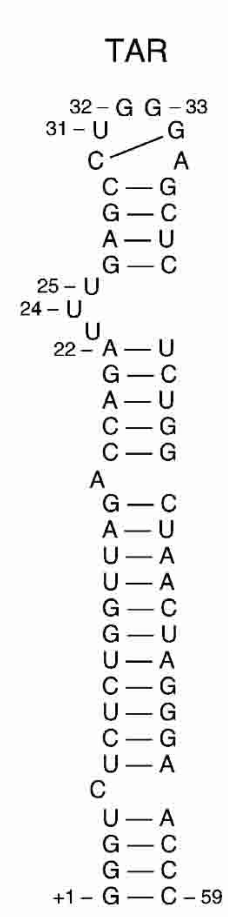

B

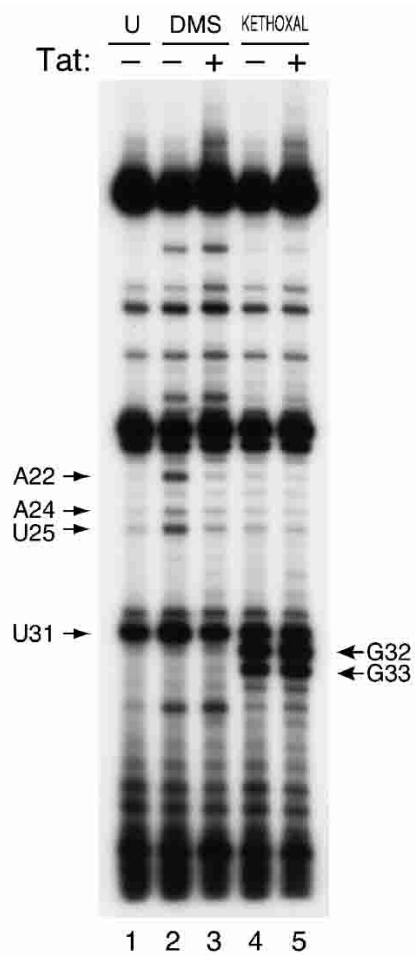

C

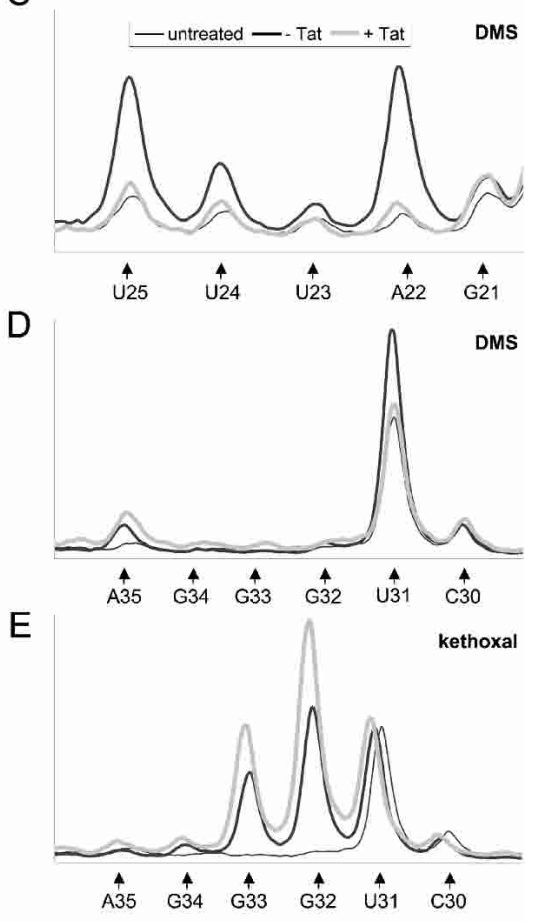

FIGURE 6. Footprinting analysis of TAR in the presence of a Tat-derived peptide. (A) Secondary structure model of the TAR hairpin as present in the HIV-1 subtype B LAI isolate. (B) Chemical structure probing of TAR RNA in the absence and presence of Tat peptide. Reactions correspond to untreated RNA (U, lane 1), DMS modification (lanes 2 and 3) and kethoxal modification (lanes 4,5) in the absence or presence of Tat peptide, as indicated on top of the lanes. Arrows indicate nucleotides that display differential modification upon Tat binding and these residues are marked in panel $A$. $(C-E)$ Densitograms of the structure-probing results highlighting DMS reactivity in the bulge region $(C)$, DMS reactivity in the loop region $(D)$, and kethoxal reactivity in the loop region $(E)$. Thin black lines correspond to the untreated control and Tat unbound and bound RNA is represented by thick black and thick grey lines, respectively.

sition 31 (not shown), demonstrating that $\mathrm{U} 31$ is indeed the position at which the cross-link occurred. Together, these results indicate that the cross-linked product X3, which is uniquely observed in the presence of the Tat peptide, represents an RNA-protein cross-link. Thus, U31 must be in close proximity to Tat in the Tat-TAR binary complex.

\section{DISCUSSION}

We provide evidence for a new (A22-U40)U31 base triple in the free HIV-1 TAR hairpin. This base triple is different from the one observed upon binding of Tat, which involves the bulge residue U23 and the A27-U38 base pair. Thus, our results suggest that TAR has the ability to adopt two different base triples, one in the absence and one in the presence of Tat. Binding of Tat is known to cause a reorientation of the TAR structure such that the helical bend is straightened and the bulge is looped out from the coaxially stacked stems (Fig. 8). This change in the tertiary structure of TAR may ensure that the (A22-U40)U31 triple is disrupted as the (A27-U38)U23 triple is formed. This offers the intriguing possibility that HIV-1 gene expression requires a tertiary structure switch between two mutually exclusive base triples in TAR.
The evidence we provide for the (A22-U40)U31 triple in the free TAR RNA derives from comparative sequence analysis, RNA structure probing, molecular modeling, and trans-activation assays. Several previous reports are also consistent with this Tat-independent base triple in TAR. For instance, NMR studies positioned the loop in the vicinity of the bulge due to the helical bending that is induced by the stacked bulge conformation in free TAR (Aboul-ela et al. 1996; Al Hashimi et al. 2002). Furthermore, the A22U40 base pair in free TAR is known to adopt an unusual conformation with a widened major groove (Weeks and Crothers 1991; Aboul-ela et al. 1995, 1996). It has also been reported that tethering of an Fe-EDTA chelate to U24 in the TAR bulge yields cleavages in the apical loop (Huq et al. 1999) and metal-ion-induced cleavages of free TAR have been mapped to the loop and bulge (Olejniczak et al. 2002). We observed that implementing the (A22-U40)U31 triple during structure modeling causes a major bend in the TAR hairpin. As the induced distortion is partially absorbed by the 3-nt bulge, the formation of the triple appears correlated with the structural changes in the bulge. This suggests that the conformational dynamics of the bulge observed in previous studies (Aboul-ela et al. 1996; Long and Crothers 1999; Al Hashimi et al. 2002) may be explained by the 
A

B

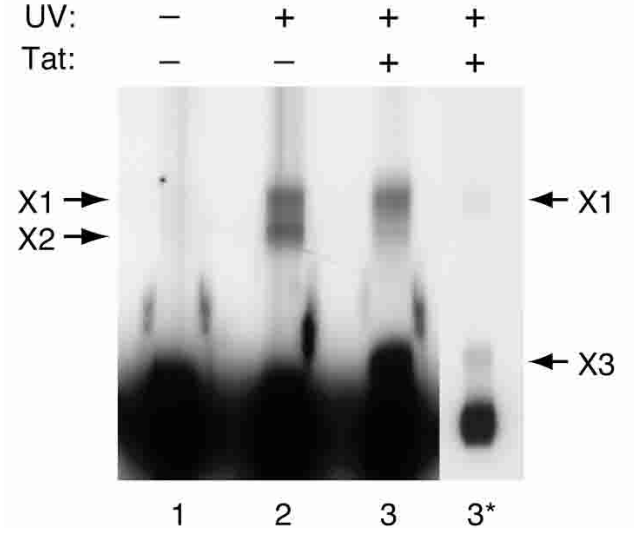

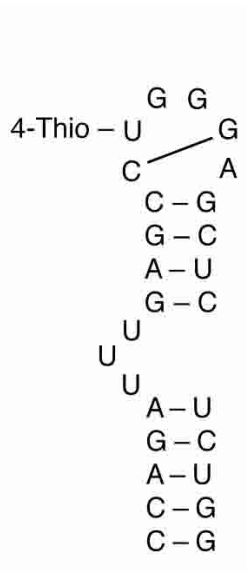
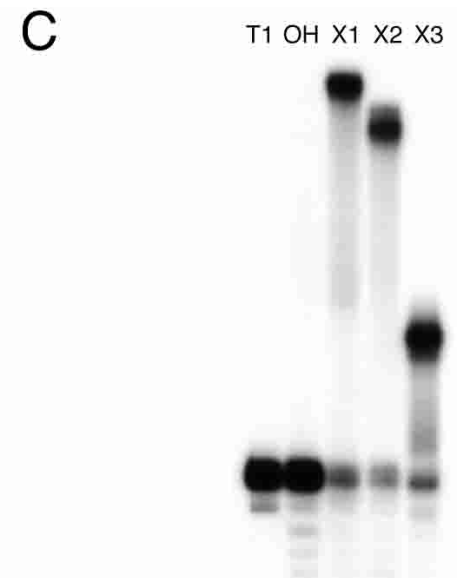

FIGURE 7. Site-specific cross-linking TAR with a 4-thiouridine at loop residue 31 in the absence and presence of Tat peptide. (A) The 27-mer TAR hairpin with the modified loop residue. $(B)$ Separation of cross-linked products on a $12 \%$ denaturing polyacrylamide gel. Samples correspond to TAR RNA without UV exposure (lane 1), TAR RNA after UV exposure in the absence (lane 2) and presence (lane 3) of Tat peptide. Three cross-linked species were identified and excised from the gel (X1, X2, and X3). Cross-link X3 appears as a smear on this gel, but was observed as a discrete band on shorter exposures (lane $3^{\star}$ ). $(C)$ Mapping of the cross-linked bases by partial hydrolysis of $5^{\prime}$-end-labeled RNA. Control lanes include a T1 digestion showing the guanosine residues (lane 1) and a partial hydrolysis ladder of uncrosslinked TAR RNA (lane 2).

ability of free TAR to adopt both the bent conformer in which the (A22-U40)U31 triple can form and the straight conformer with the (A27-U38)U23 triple in solution.

Mutational disruption of the (A22-U40)U31 base triple diminishes reporter activity in LTR-luciferase assays, which is rescued in the mutant with a reconstituted (G22-C40)C31 triple that is also present in natural HIV-1 isolates of the $\mathrm{O}$ group. We note that the reporter activity of all the mutants was only moderately reduced compared to wild-type TAR. It is therefore unlikely that these mutations have a severe impact on the interaction of TAR with Tat. Indeed, none of the mutants have a defect in binding of the Tat peptide, which is consistent with previous studies (Weeks and Crothers 1991, 1992; Delling et al. 1992; Churcher et al.

1993). This suggests that the bent TAR conformation with the (A22-U40)U31 triple affects steps in HIV-1 gene expression other than Tat-mediated trans-activation. The base triple that we propose may constitute a binding site for a cellular protein involved in HIV-1 gene expression, but this need not necessarily be a component of the transcriptional machinery. For example, the eukaryotic translation initiation factor 2 (eIF2) binds to TAR in a structure-specific manner, and mutational disruption of this interaction decreases the translational efficiency (Ben Asouli et al. 2000).

We observed that binding of a Tat peptide to TAR results in protection of the bulge residues from chemical modification, and this coincides with differential reactivities in the apical loop. Loop residue U31 is protected from chemical modification in the presence of the peptide, and subsequent crosslinking experiments indicated that this loop residue is in close proximity to the peptide. In previous studies, cross-linking of a 4-thiouridine-substituted TAR at position 31, identical to the RNA used in this study, was performed with an 86amino-acid Tat protein (Richter et al. 2002b) and a 35-amino-acid Tat-derived peptide (Wang et al. 1999). Because we used a 13-amino-acid Tat-derived peptide, we can narrow the loopprotein interaction down to the arginine-rich motif in Tat, which is consistent with the proposal that Arg57 contacts U31 in the apical loop (Wang et al. 1999). The study of Richter and coworkers indicates that TAR crosslinks less efficiently to Tat than to cyclin T1, which binds to the TAR loop (Richter et al. 2002b). The interaction of Tat with the loop may thus be rather weak, which is consistent with reports showing that mutations in the TAR loop have a negligible effect on the affinity for Tat (Dingwall et al. 1990; Roy et al. 1990; Sumner-Smith et al. 1991). Interestingly, a recent in vivo study proposed an interaction of Tat with the TAR loop, based on swapping experiments with the equine infectious anemia virus (EIAV) Tat protein and TAR RNA (Lund et al. 2003).

We propose that the highly bent structure of the HIV-1 TAR hairpin in the absence of Tat coincides with the formation of a (A22-U40)U31 base triple. Binding of Tat to TAR results in disruption of this triple by straightening of the hairpin, causing a reorientation of the A22-U40 base 
A

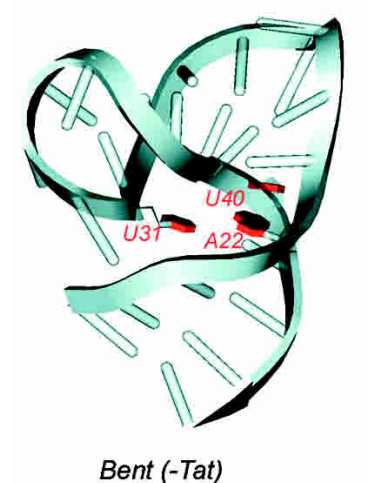

Bent (-Tat)

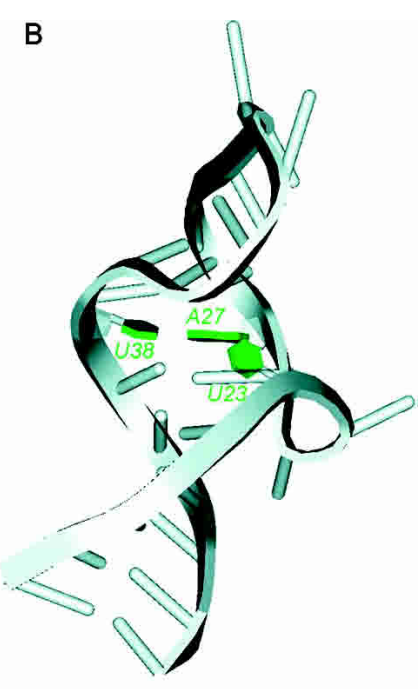

Straight (+Tat)

FIGURE 8. Structure models for the bent and straight conformations of the HIV-1 TAR hairpin. (A) The bent TAR structure with the (A22-U40)U31 triple can fold in the absence of the Tat protein and is derived from the structure modeling described in the text. (B) A straight conformer of TAR bound by the Tat-mimic argininamide (Puglisi et al. 1992), which forms the (A27-U38)U23 base triple.

pair and shielding of U31 by the protein. Furthermore, Tat facilitates the formation of the base triple involving residues U23, A27, and U38. We cannot currently foresee how such a tertiary structure switch may be operational in the biology of HIV-1. In particular, it is unclear whether the (A22U40)U31 triple is functional prior to or after the interaction of the Tat protein with TAR. Identification of a factor that specifically binds the bent TAR structure may shed light on this intriguing new feature of the HIV-1 TAR element.

\section{MATERIALS AND METHODS}

\section{Comparative sequence analysis}

Sequences of different HIV-1 isolates were obtained from the HIV database at Los Alamos (http://-web.lanl.gov/). Only isolates with a complete TAR sequence were considered in the analysis, yielding a total of 722 sequences from most of the prevailing HIV-1 subtypes.

\section{Plasmid constructs}

The pBlue3'LTR-luc plasmid contains an XhoI-HindIII fragment of the HIV-1 LAI proviral DNA, encoding the complete U3 region, the transcription start site $(+1)$, and $\mathrm{R}$ sequences up to position +82 , coupled to the Firefly luciferase reporter gene (Jeeninga et al. 2000). For mutation of the TAR hairpin, a PCR was performed with the primer LAI5'X (5'-CATTCTAGATGGAAGGGCTAATT CACTCCC- $3^{\prime}$ ) and one of the following mutagenic primers (substituted nucleotides underlined):

R80/16WT: 5'-GCTTTATTGAGGCTTAAGCAGTGGGTTCCC TAGTTAGCCAGAGAGCTCCCAGGCTCAAATCTGGTC-3', R80/61MUT1: 5'-GCTTTATTGAGGCTTAAGCAGTGGGTTCC CTAGTTAGCCAGAGAGCTCCCGGGCTCAAATCTGGTC-3', R80/61MUT2: 5'-GCTTTATTGAGGGCTTAAGCAGTGGGTTCC CTAGTTAGCCAGGGAGCTCCCGGGCTCAAACCTGGTC-3', R80/61MUT3: 5'-GCTTTATTGAGGCTTAAGCAGTGGGTTCC CTAGTTAGCCAGGGAGCTCCCAGGCTCAAACCTGGTC-3', R80/61MUT4: 5'-GC̄TTTATTGAGGCTTAAGCĀGTGGGTTCC CTAGTTAGCCAGTGAGCTCCCAGGCTCAAAACTGGTC-3'.

The PCR fragments were digested with BfrI and DraIII and cloned in the corresponding sites of pBlue3'LTR-luc. All mutations were verified by sequence analysis. The $\mathrm{pRL}-\mathrm{CMV}$ plasmid contains the Renilla luciferase reporter gene under the control of the CMV promoter and is used as an internal control reporter plasmid in transfection assays. pcDNA3-Tat expresses the HIV-1 LAI Tat gene from the CMV promoter (Verhoef et al. 1997).

\section{RNA structure probing}

For chemical structure probing, $2 \mu \mathrm{g}$ of in vitro synthesized RNA corresponding to the first $80 \mathrm{nt}$ of HIV-1 transcripts (1-80) was dissolved in water and heated to $80^{\circ} \mathrm{C}$. Tubes were then placed in a $60^{\circ} \mathrm{C}$ water bath, buffer was added, and the solution was allowed to slowly cool to $37^{\circ} \mathrm{C}$. Final solutions contained $50 \mathrm{mM} \mathrm{Na}$ Cacodylate buffer ( $\mathrm{pH} 7.2$ ), $1.0 \mathrm{mM} \mathrm{MgCl}_{2}, 1 \mathrm{mM} \mathrm{DTT}$, and $10 \%$ glycerol in a total volume of $100 \mu \mathrm{L}$. In footprinting experiments, $5 \mu \mathrm{g}$ of the B13 Tat peptide was added. A volume of $1.0 \mu \mathrm{L}$ of DMS, DEPC, or kethoxal was added and allowed to react for $5 \mathrm{~min}$ (DMS) or $15 \mathrm{~min}$ (DEPC and kethoxal). Reactions were stopped by addition of $5 \mu \mathrm{L}$ of total E. coli tRNA $(10 \mu \mathrm{g} / \mu \mathrm{L}$. The samples were treated with proteinase $\mathrm{K}$ and SDS to remove protein and subsequently precipitated with ammonium acetate and ethanol. The precipitated RNA was dissolved in $10 \mu \mathrm{L}$ water, of which $2 \mu \mathrm{L}$ were used for primer extension. The primer R80/61 anneals to nt 61-80 of the transcript. Reverse transcription with AMV Reverse Transcriptase was performed as described previously (Huthoff and Berkhout 2001). Samples were precipitated and loaded on a $10 \%$ denaturing polyacrylamide gel. The intensity of RT stops caused by base modification was analyzed on a Storm 860 phosphorimager.

\section{Cells and transfection}

Transfection of C33A was performed by the calcium phosphate method as previously described (Das et al. 1999). The transcriptional activity of the wild-type and TAR-mutated HIV-1 LTRs was determined by transfection of C33A cells with $20 \mathrm{ng}$ wild-type or mutant TAR pBlue3'LTR-luc, $2.5 \mathrm{ng}$ pRL-CMV, with or without $30 \mathrm{ng}$ pcDNA3-Tat and $1.0 \mu \mathrm{g}$ of the empty pBluescript. At $2 \mathrm{~d}$ after transfection, cells were isolated by centrifugation at $260 \mathrm{~g}$ for 10 min. The Dual-Luciferase Reporter Assay System was used to determine the Firefly and Renilla luciferase levels.

\section{Tat protein band shifts}

For protein band shifts we used the Consensus B Tat-13 peptide with the sequence H-Arg-Lys-Lys-Arg-Arg-Gln-Arg-Arg-Arg-Pro- 
Gln-Asp-Ser-Gln-OH. The peptide was dissolved in water to a concentration of $1 \mu \mathrm{g} / \mu \mathrm{L}$ and aliquots were stored at $-80^{\circ} \mathrm{C}$. Radiolabeled TAR RNA ( $250 \mathrm{ng}$ ) was refolded by heating to $80^{\circ} \mathrm{C}$, addition of Tat binding buffer $(25 \mathrm{mM}$ Tris- $\mathrm{HCl}$ at $\mathrm{pH} 7.5,100$ $\mathrm{mM} \mathrm{KCl}, 1 \mathrm{mM} \mathrm{MgCl}_{2}, 1 \mathrm{mM} \mathrm{DTT}, 10 \%$ glycerol) and subsequent slow cooling from $60^{\circ} \mathrm{C}$ to $37^{\circ} \mathrm{C}$. Tat peptide $(0.5 \mu \mathrm{g})$ was added at $37^{\circ} \mathrm{C}$ and incubated for $30 \mathrm{~min}$. The total volume of the samples was $10 \mu \mathrm{L}$. After the incubation, an equal volume of loading buffer was added and samples were analyzed on $4 \%$ nodenaturing polyacrylamide gel $(0.25 \times \mathrm{TBE})$ that was run at room temperature.

\section{Structure modeling}

The 20 deposited TAR structures (Aboul-ela et al. 1996), as well as their enclosed data set (Research Collaboratory for Structural Bioinformatics website AN: 1ANR), were used as starting material. We considered three different cases in our structure modeling. First, we used the published NMR structural restraints to ensure that calculated structures display similar space sampling and root mean square deviations (RMSD) as the published structural ensemble. Second, additional restraints were introduced to allow C30-G34 base pairing in a Watson-Crick fashion $\left(\mathrm{CG}^{\text {cross }}\right)$. Third, the C30-G34 pair was formed in combination with the base-triple type involving residues A22, U31, and U40 ((A-U)U + CG $\left.{ }^{\text {cross }}\right)$. In addition to the NMR experimental restraints, mild planarity was imposed on base-paired residues to ensure better helical twist parameters and to prevent possible base distortion. In each case, 100 molecules were calculated via the following simulated annealing protocol: The starting structures were submitted to a torsion angle dynamic (TAD) protocol performed with XPLOR version 3.851 (Brunger 1992). Temperature was raised from $300 \mathrm{~K}$ to $20,000 \mathrm{~K}$ in 40 steps (total duration of $30 \mathrm{psec}$ ), with a stepwise increase of NOE energy from 5 to $150 \mathrm{Kcal} \cdot \mathrm{mole}^{-1} \cdot \AA^{-2}$. The initial steps, carried out under low NOE energy, ensured randomization of the backbone angle but kept the structures partially folded. During a slow cooling period, the temperature was scaled down to $1000 \mathrm{~K}$, keeping high NOE energy $\left(150 \mathrm{Kcal} \cdot \mathrm{mole}^{-1} \cdot \AA^{-2}\right)$ and low dihedral force constant $\left(5 \mathrm{Kcal} \cdot \mathrm{mole}{ }^{-1} \cdot \mathrm{rad}^{-2}\right)$. After switching to Cartesian space, the system was submitted to 3 psec restrained molecular dynamic (rMD) during which the molecules were cooled down to $300 \mathrm{~K}$, the NOE and dihedral energy terms were respectively rescaled to $50 \mathrm{Kcal} \cdot \mathrm{mole}^{-} 1 \cdot \AA^{-2}$ and $200 \mathrm{Kcal}$. mole ${ }^{-1} \cdot \mathrm{rad}^{-2}$. A last step of $2 \mathrm{psec}$ of $\mathrm{rMD}$ at $300 \mathrm{~K}$ was carried out for equilibration with the final energy term values and calculation was concluded by 1000 steps of Powell minimization.

\section{Convergence of models}

When the C30-G34 base pair was imposed alone, 59 out of 100 structures respected the acceptance criteria, that is, no NOE violation $0.5 \AA$ and no dihedral violation $2^{\circ}$. When the cross-loop and triple interactions were imposed simultaneously, 28 out of 100 structures converged to low energies with no restraint violations. For $(\mathrm{A}-\mathrm{U}) \mathrm{U}+\mathrm{CG}^{\text {cross }}$, the NOE energy term was on average two times higher than for $\mathrm{CG}^{\text {cross }}$, that is, $\sim 60 \mathrm{Kcal} \cdot \mathrm{mole}^{-1}$ instead of $\sim 30 \mathrm{Kcal} \cdot \mathrm{mole}^{-1}$. The two final sets of structures consist of the 20 best models according to the lowest global energy and the absence of structural restraint violations. In both families of converged models, the RMSD for the first stem (residues 17-21/41-45) remains around $1.00 \AA$. A similar RMSD was calculated for the upper stem (residues 26-29/36-39) in the $C^{\text {cross }}$ ensemble. For the $(\mathrm{A}-\mathrm{U}) \mathrm{U}+\mathrm{CG}^{\text {cross }}$ ensemble, a slightly larger RMSD was obtained for this stem. Nevertheless, it was scaled down to $\sim 1.00 \AA$ when we considered the 15 best structures instead of 20 . The definition of the lower part of loop (29-30/34-36) was significantly improved by distance restraints imposed on residues C30 and G34, with an RMSD of $\sim 1.2 \AA$.

\section{${ }^{1} \mathrm{H}-{ }^{1} \mathrm{H}$ distance validation}

To validate the consistency of the structural ensembles with the published TAR NMR data set, we checked whether the $\mathrm{CG}^{\text {cross }}$ and $(\mathrm{A}-\mathrm{U}) \mathrm{U}+\mathrm{CG}^{\text {cross }}$ restraints would introduce short nonexchangeable proton-proton distances not described in the previous NMR studies (Long and Crothers 1999). MOLMOL (Koradi et al. 1996) was used to extract all nonexchangeable ${ }^{1} \mathrm{H}-{ }^{1} \mathrm{H}$ distances $<5 \AA$ among the three ensembles. Every short distance observed in at least $50 \%$ of the molecules of the ensemble was considered as being observable by a NOESY type experiment. In the absence of a match between the observed NOE and back-calculated distances, we subsequently checked if such a short distance was also present in the published TAR 20 structures ensemble (1ANR). If so, it was considered as nonconflicting with the previous studies.

\section{Chemical shifts analysis}

The reliability of the structural ensembles was also assessed by NMR chemical shifts (CSS) prediction. CCS were back-calculated from the structures with NUCHEMICS, considering ring-current effects, magnetic-anisotropy terms, and ignoring charge contribution (Wijmenga et al. 1997; Cromsigt et al. 2001). Each proton shift, calculated for every converged molecule, was averaged among the ensemble of 20 calculated structures. Absolute deviation of back-calculated (CCS ${ }^{\text {back }}$ ) from the experimental chemical shifts $\left(\mathrm{CCS}^{\exp }\right)$ was computed for each nucleotide and normalized to one proton.

\section{Site-specific cross-linking}

The 27-mer TAR RNA (5'-CCAGAUUUGAGCCU ${ }^{*}$ GGGAGCU CUCUGG-3', $\mathrm{U}^{*}$ being 4 -thiouridine) was purchased from Eurogentec. This RNA was $5^{\prime}$-end labeled with the Ambion Kinasemax kit and $3^{\prime}$-end labeled with NEB T4 RNA ligase according to the manufacturer's instructions. End-labeled RNA was excised from a $12 \%$ denaturing polyacrylamide gel and eluted from the gel slice by overnight incubation in $400 \mu \mathrm{L}$ TBE at $4^{\circ} \mathrm{C}$. After ethanol precipitation and washing, the RNA was dissolved in $15 \mu \mathrm{L}$ nuclease-free water. The RNA ( $2 \mu \mathrm{g})$ was refolded by heating to $80^{\circ} \mathrm{C}$, addition of Tat binding buffer, and subsequent slow cooling from $60^{\circ} \mathrm{C}$ to $37^{\circ} \mathrm{C}$. Tat peptide $(5 \mu \mathrm{g})$ was added at $37^{\circ} \mathrm{C}$ and the sample (total volume $25 \mu \mathrm{L}$ ) was incubated for $30 \mathrm{~min}$. For cross-linking, the samples were placed on ice and exposed to UV light of $366 \mathrm{~nm}$ for $20 \mathrm{~min}$. The UV source was placed directly at the opening of the Eppendorf tubes. After UV exposure, the samples were treated with proteinase K/SDS to remove protein. Samples were loaded on a $12 \%$ polyacrylamide gel from which cross-linked and noncross- 
linked RNA species were excised. To identify the cross-link position, T1 sequencing and partial hydrolysis reactions were performed as described previously (Hargittai et al. 2001). These samples were analyzed on an $18 \%$ denaturing polyacrylamide gel, which was exposed on a Storm 860 phosphorimager and analyzed with Imagequant software.

\section{ACKNOWLEDGMENTS}

We thank Wim van Est for preparing the figures and Atze Das for assistance with the cell culture experiments. This work was supported by the Netherlands Organization for Scientific Research (NWO-CW). The following reagent was obtained through the NIH AIDS Research and Reference program, Division of AIDS, NIAID, NIH: Consensus B Tat-13 peptide from DIADS, NIAID.

The publication costs of this article were defrayed in part by payment of page charges. This article must therefore be hereby marked "advertisement" in accordance with 18 USC section 1734 solely to indicate this fact.

Received August 21, 2003; accepted November 4, 2003.

\section{REFERENCES}

Aboul-ela, F., Karn, J., and Varani, G. 1995. The structure of the human immunodeficiency virus type 1 TAR RNA reveals principles of RNA recognition by Tat protein. J. Mol. Biol. 253: 313332.

-1996. Structure of HIV-1 TAR RNA in the absence of ligands reveals a novel conformation of the trinucleotide bulge. Nucleic Acids Res. 24: 3974-3981.

Al Hashimi, H.M., Gosser, Y., Gorin, A., Hu, W., Majumdar, A., and Patel, D.J. 2002. Concerted motions in HIV-1 TAR RNA may allow access to bound state conformations: RNA dynamics from NMR residual dipolar couplings. J. Mol. Biol. 315: 95-102.

Babin, P., Dolan, M., Wollenzien, P., and Gutell, R.R. 1999. Identity and geometry of a base triple in $16 \mathrm{~S}$ rRNA determined by comparative sequence analysis and molecular modeling. RNA 5: 14301439.

Ben Asouli, Y., Banai, Y., Hauser, H., and Kaempfer, R. 2000. Recognition of $5^{\prime}$-terminal TAR structure in human immunodeficiency virus-1 mRNA by eukaryotic translation initiation factor 2. Nucleic Acids Res. 28: 1011-1018.

Berkhout, B. and Jeang, K.T. 1991. Detailed mutational analysis of TAR RNA: Critical spacing between the bulge and loop recognition domains. Nucleic Acids Res. 19: 6169-6176.

Berkhout, B., Silverman, R.H., and Jeang, K.T. 1989. Tat trans-activates the human immunodeficiency virus through a nascent RNA target. Cell 59: 273-282.

Bieniasz, P.D., Grdina, T.A., Bogerd, H.P., and Cullen, B.R. 1999. Recruitment of cyclin T1/P-TEFb to an HIV type 1 long terminal repeat promoter proximal RNA target is both necessary and sufficient for full activation of transcription. Proc. Natl. Acad. Sci. 96: 7791-7796.

Brodsky, A.S., Erlacher, H.A., and Williamson, J.R. 1998. NMR evidence for a base triple in the HIV-2 TAR C-G.C+ mutant-argininamide complex. Nucleic Acids Res. 26: 1991-1995.

Brunger, A.T. 1992. X-PLOR, Version 3.1: A system for X-ray crystallography and NMR. Yale University Press, New Haven, CT.

Calnan, B.J., Tidor, B., Biancalana, S., Hudson, D., and Frankel, A.D. 1991. Arginine-mediated RNA recognition: The arginine fork. Science 252: 1167-1171.

Churcher, M.J., Lamont, C., Hamy, F., Dingwall, C., Green, S.M., Lowe, A.D., Butler, J.G., Gait, M.J., and Karn, J. 1993. High affinity binding of TAR RNA by the human immunodeficiency virus type-1 tat protein requires base-pairs in the RNA stem and amino acid residues flanking the basic region. J. Mol. Biol. 230: 90-110.

Colvin, R.A. and Garcia-Blanco, M.A. 1992. Unusual structure of the human immunodeficiency virus type 1 trans-activation response element. J. Virol. 66: 930-935.

Critchley, A.D., Haneef, I., Cousens, D.J., and Stockley, P.G. 1993. Modeling and solution structure probing of the HIV-1 TAR stemloop. J. Mol. Graph. 11: 92-97.

Cromsigt, J.A.M.T.C., Hilbers, C.W., and Wijmenga, S.S. 2001. Prediction of proton chemical shifts in RNA. J. Biomol. NMR 21: 1129.

Cullen, B.R. 1998. HIV-1 auxiliary proteins: Making connections in a dying cell. Cell 93: 685-692.

Das, A.T., Klaver, B., and Berkhout, B. 1999. A hairpin structure in the $\mathrm{R}$ region of the Human Immunodeficiency Virus type 1 RNA genome is instrumental in polyadenylation site selection. J. Virol. 73: 81-91.

Delling, U., Reid, L.S., Barnett, R.W., Ma, M.Y., Climie, S., SumnerSmith, M., and Sonenberg, N. 1992. Conserved nucleotides in the TAR RNA stem of human immunodeficiency virus type 1 are critical for Tat binding and trans activation: Model for TAR RNA tertiary structure. J. Virol. 66: 3018-3025.

Dimitrov, D.S., Willey, R.L., Sato, H., Chang, L.-J., Blumenthal, R., and Martin, M.A. 1993. Quantitation of human immunodeficiency virus type 1 infection kinetics. J. Virol. 67: 2182-2190.

Dingwall, C., Ernberg, I., Gait, M.J., Green, S.M., Heaphy, S., Karn, J., Lowe, A.D., Singh, M., Skinner, M.A., and Valerio, R. 1989. Human Immunodeficiency Virus 1 tat protein binds trans-activatingresponsive region (TAR) RNA in vitro. Proc. Natl. Acad. Sci. 86: 6925-6929.

Dingwall, C., Ernberg, I., Gait, M.J., Green, S.M., Heaphy, S., Karn, J., Lowe, A.D., Singh, M., and Skinner, M.A. 1990. HIV-1 tat protein stimulates transcription by binding to a U-rich bulge in the stem of the TAR RNA structure. EMBO J. 9: 4145-4153.

Feng, S. and Holland, E.C. 1988. HIV-1 tat trans-activation requires the loop sequence within tar. Nature 334: 165-167.

Fisher, A.G., Feinberg, M.B., Josephs, S.F., Harper, M.E., Marselle, L.M., Reyes, G., Gonda, M.A., Aldovini, A., Debouck, C., and Gallo, R.C. 1986. The trans-activator gene of HTLV-III is essential for virus replication. Nature 320: 367-371.

Gautheret, D., Damberger, S.H., and Gutell, R.R. 1995. Identification of base-triples in RNA using comparative sequence analysis. J. Mol. Biol. 248: 27-43.

Gultyaev, A.P., Franch, T., and Gerdes, K. 2000. Coupled nucleotide covariations reveal dynamic RNA interaction patterns. RNA 6: 1483-1491.

Hargittai, M.R., Mangla, A.T., Gorelick, R.J., and Musier-Forsyth, K. 2001. HIV-1 nucleocapsid protein zinc finger structures induce tRNA(Lys,3) structural changes but are not critical for primer/ template annealing. J. Mol. Biol. 312: 985-997.

Harper, J.W. and Logsdon, N.J. 1991. Refolded HIV-1 tat protein protects both bulge and loop nucleotides in TAR RNA from ribonucleolytic cleavage. Biochemistry 30: 8060-8066.

Hennig, M. and Williamson, J.R. 2000. Detection of N-H. . .N hydrogen bonding in RNA via scalar couplings in the absence of observable imino proton resonances. Nucleic Acids Res. 28: 1585-1593.

Huq, I., Tamilarasu, N., and Rana, T.M. 1999. Visualizing tertiary folding of RNA and RNA-protein interactions by a tethered iron chelate: Analysis of HIV-1 Tat-TAR complex. Nucleic Acids Res. 27: 1084-1093.

Huthoff, H. and Berkhout, B. 2001. Two alternating structures for the HIV-1 leader RNA. RNA 7: 143-157.

Ippolito, J.A. and Steitz, T.A. 1998. A 1.3-Å resolution crystal structure of the HIV-1 trans-activation response region RNA stem reveals a metal ion-dependent bulge conformation. Proc. Natl. Acad. Sci. USA 95: 9819-9824.

Jaeger, J.A. and Tinoco Jr., I., 1993. An NMR study of the HIV-1 TAR element hairpin. Biochemistry 32: 12522-12530. 
Jeeninga, R.E., Hoogenkamp, M., Armand-Ugon, M., de Baar, M., Verhoef, K., and Berkhout, B. 2000. Functional differences between the LTR transcriptional promoters of HIV-1 subtypes A through G. J. Virol. 74: 3740-3751.

Koradi, R., Billeter, M., and Wuthrich, K. 1996. MOLMOL: A program for display and analysis of macromolecular structures. J. Mol. Graph. 14: 51-32.

Kulinski, T., Olejniczak, M., Huthoff, H., Bielecki, L., Pachulska-Wieczorek, K., Das, A.T., Berkhout, B., and Adamiak, R.W. 2003. The apical loop of the HIV-1 TAR RNA hairpin is stabilized by a cross-loop base pair. J. Biol. Chem. 278: 38892-38901.

Long, K.S. and Crothers, D.M. 1999. Characterization of the solution conformations of unbound and Tat peptide-bound forms of HIV-1 TAR RNA. Biochemistry 38: 10059-10069.

Lund, L.H., Wahren, B., and Garcia-Blanco, M.A. 2003. A functional genetic approach suggests a novel interaction between the human immunodeficiency virus type 1 (HIV-1) Tat protein and HIV-1 TAR RNA in vivo. J. Gen. Virol. 84: 603-606.

Marciniak, R.A. and Sharp, P.A. 1991. HIV-1 Tat protein promotes formation of more-processive elongation complexes. EMBO J. 10: 4189-4196.

Mathews, D.H., Sabina, J., Zuker, M., and Turner, D.H. 1999. Expanded sequence dependence of thermodynamic parameters improves prediction of RNA secondary structure. J. Mol. Biol. 288: 911-940.

Muesing, M.A., Smith, D.H., and Capon, D.J. 1987. Regulation of mRNA accumulation by a human immunodeficiency virus transactivator protein. Cell 48: 691-701.

Nifosi, R., Reyes, C.M., and Kollman, P.A. 2000. Molecular dynamics studies of the HIV-1 TAR and its complex with argininamide. Nucleic Acids Res. 28: 4944-4955.

Olejniczak, M., Gdaniec, Z., Fischer, A., Grabarkiewicz, T., Bielecki, L., and Adamiak, R.W. 2002. The bulge region of HIV-1 TAR RNA binds metal ions in solution. Nucleic Acids Res. 30: 4241-4249.

Parada, C.A. and Roeder, R.G. 1996. Enhanced processivity of RNA polymerase II triggered by Tat-induced phosphorylation of its carboxy-terminal domain. Nature 384: 375-378.

Puglisi, J.D., Tan, R., Calnan, B.J., Frankel, A.D., and Williamson, J.R. 1992. Conformation of the TAR RNA-arginine complex by NMR spectroscopy. Science 257: 76-80.

Puglisi, J.D., Chen, L., Frankel, A.D., and Williamson, J.R. 1993. Role of RNA structure in arginine recognition of TAR RNA. Proc. Natl. Acad. Sci. 90: 3680-3684.

Richter, S., Cao, H., and Rana, T.M. 2002a. Specific HIV-1 TAR RNA loop sequence and functional groups are required for human cyclin T1-Tat-TAR ternary complex formation. Biochemistry 41: 6391-6397.

Richter, S., Ping, Y.H., and Rana, T.M. 2002b. TAR RNA loop: A scaffold for the assembly of a regulatory switch in HIV replication. Proc. Natl. Acad. Sci. 99: 7928-7933.

Roy, S., Delling, U., Chen, C.H., Rosen, C.A., and Sonenberg, N. 1990. A bulge structure in HIV-1 TAR RNA is required for Tat binding and Tat-mediated trans-activation. Genes \& Dev. 4: 1365-1373.

Sumner-Smith, M., Roy, S., Barnett, R., Reid, L.S., Kuperman, R., Delling, U., and Sonenberg, N. 1991. Critical chemical features in trans-acting-responsive RNA are required for interaction with human immunodeficiency virus type 1 Tat protein. J. Virol. 65: 51965202.

Tanner, M.A., Anderson, E.M., Gutell, R.R., and Cech, T.R. 1997. Mutagenesis and comparative sequence analysis of a base triple joining the two domains of group I ribozymes. RNA 3: 1037-1051.

Tao, J. and Frankel, A.D. 1992. Specific binding of arginine to TAR RNA. Proc. Natl. Acad. Sci. 89: 2723-2726.

Verhoef, K., Koper, M., and Berkhout, B. 1997. Determination of the minimal amount of Tat activity required for human immunodeficiency virus type 1 replication. Virology 237: 228-236.

Wang, Z., Huq, I., and Rana, T.M. 1999. Proximity of a Tat peptide to the HIV-1 TAR RNA loop region determined by site-specific photo-cross-linking. Bioconjug. Chem. 10: 512-519.

Weeks, K.M. and Crothers, D.M. 1991. RNA recognition by Tatderived peptides: Interaction in the major groove. Cell 66: $577-$ 588 .

- 1992. RNA binding assays for Tat-derived peptides: Implications for specificity. Biochemistry 31: 10281-10287.

Weeks, K.M., Ampe, C., Schultz, S.C., Steitz, T.A., and Crothers, D.M. 1990. Fragments of the HIV-1 Tat protein specifically bind TAR RNA. Science 249: 1281-1285.

Wei, P., Garber, M.E., Fang, S.-M., Fisher, W.H., and Jones, K.A. 1998. A novel CDK9-associated C-type cyclin interacts directly with HIV-1 Tat and mediates its high-affinity, loop-specific binding to TAR RNA. Cell 92: 451-462.

Wijmenga, S.S., Kruithof, M., and Hilbers, C.W. 1997. Analysis of H-1 chemical shifts in DNA: Assessment of the reliability of $\mathrm{H}-1$ chemical shift calculations for use in structure refinement. J. Biomol. NMR 10: 337-350.

Zacharias, M. and Hagerman, P.J. 1995. The bend in RNA created by the trans-activation response element bulge of human immunodeficiency virus is straightened by arginine and by Tat-derived peptide. Proc. Natl. Acad. Sci. 92: 6052-6056.

Zuker, M. 1989. On finding all suboptimal foldings of an RNA molecule. Science 244: 48-52.

Zuker, M. and Turner, D.H. 1999. Algorithms and thermodynamics for RNA secondary structure prediction: A practical guide. In RNA biochemistry and biotechnology (eds. J. Barciszewski and B.F.C. Clark), pp. 11-43. Kluwer Academic Publishers, Dordrecht/Boston/London. 

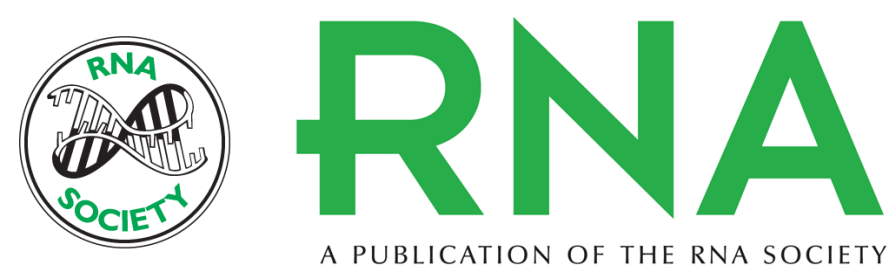

\title{
Evidence for a base triple in the free HIV-1 TAR RNA
}

\author{
HENDRIK HUTHOFF, FREDERIC GIRARD, SYBREN S. WIJMENGA, et al.
}

RNA 2004 10: 412-423

References This article cites 59 articles, 23 of which can be accessed free at:

http://rnajournal.cshlp.org/content/10/3/412.full.html\#ref-list-1

\section{License} Email Alerting
Service

To subscribe to $R N A$ go to:

http://rnajournal.cshlp.org/subscriptions 